\title{
Awareness of Breast Cancer and its Early Detection Measures among Female Students, Northern Ethiopia
}

\author{
Tesfay Hailu ${ }^{1}$, Hailemariam Berhe ${ }^{2}$, Desta Hailu ${ }^{3}$ \\ ${ }^{1,2}$ Department of Nursing, Mekelle University, Mekelle, Ethiopia \\ ${ }^{3}$ Department of Nursing, Arb Aminch University, Arb Aminch, Ethiopia
}

\begin{abstract}
Article Info
Article history:

Received Jun 12, 2016

Revised Aug 20, 2016

Accepted Aug 26, 2016

\section{Keyword:}

Awareness

Breast cancer

Detection measures

Self examination

ABSTRACT

Globally breast cancer is the most common of all cancers. Since risk reduction strategies cannot eliminate the majority of breast cancers, early detection remains the cornerstone of breast cancer control. This paper, therefore, attempts to assess the awareness of breast cancer and its early detection measures among female students in Mekelle University, Ethiopia. An institution based cross-sectional study was conducted on randomly selected female students. Multistage sampling technique was employed to select the participants. A pre-tested structured questionnaire was used. Data analysis was carried out using SPSS version 16. In this study, 760 students participated making a response rate of 96\%. Respondents with good knowledge score for risk factors, early detections measures and warning signs of breast cancer were $1.4 \%, 3.6 \%$ and $22.1 \%$ respectively. The majority $477(62.8 \%)$ of participants practiced self-breast examination. In conclusion the participants had poor knowledge of risk factors, early detection measures and early warning signs of breast cancer.Therefore, the Ministry of health of Ethiopia together with its stalk holders should strengthen providing IEC targeting women to increase their awareness about breast cancer and its early detection measure.
\end{abstract}

Copyright $@ 2016$ Institute of Advanced Engineering and Science. All rights reserved.

\section{Corresponding Author:}

Desta Hailu,

Department of Nursing,

Arba Minch University,

P.O.Box 21, Southern Ethiopia.

Email: destahailu19@gmail.com

\section{INTRODUCTION}

Breast cancer, one of the non-communicable diseases, is the most common cancer in women worldwide.It accountss for over one million of the estimated 10 million neoplasms diagnosed worldwide each year [1]. Incidence rates vary greatly worldwide from 19.3 per 100,000 women in Eastern Africa to 89.7 per 100,000 women in Western Europe. In most of the developing regions the incidence rates are below 40 per 100,000. Even though it is generally increasing, the lowest incidence rates are found in most African countries [2]. It has been estimated that one out of every nine women living in western countries is likely to be affected by breast cancer in her lifetime. The incidence of breast cancer varies between countries; the highest rates occur in the United States and Canada and, the lowest rate is found in Asia [3]. Hospital records show that in Ethiopia there are more than 200,000 cancer cases per year where cervical \& breast cancers are the top two cancer types having a lion's share for the high maternal deaths in the country [4].

Breast cancer is the primary cause of cancer death among women globally.It is estimated thatover 508, 000 women died in 2011 due to breast cancer worldwide. Although breast cancer is thought to be a disease of the developed world, almost $50 \%$ of breast cancer cases and $58 \%$ of deaths occur in less developed countries [2]. Breast cancer survival rates vary greatly worldwide, ranging from $80 \%$ or over in North America, Sweden and Japan to around $60 \%$ in middle-income countries and below $40 \%$ in low-income 
countries. The low survival rates in less developed countries can be explained mainly by the lack of early detection programme, resulting in a high proportion of women presenting with late-stage disease, as well as by the lack of adequate diagnosis and treatment facilities [2].

Established risk factors of breast cancer are a familial history of breast cancer, prolonged exposure to endogenous estrogens, such as early menarche, late menopause, late age at first childbirth ,Exogenous hormone, Oral contraceptive and hormone replacement therapy. Breastfeeding, weight control, physical activity, and avoidance of smoking also have a protective effect [2].

Although risk reduction might be achieved with prevention, these strategies cannot eliminate the majority of breast cancers that develop in low and middle income countries. Therefore, the key strategy in reducing breast cancer related mortality, improving breast cancer outcome and survival is screening to early detect and manage breast cancer. This is very important because an excellent prognosis is directly associated with the stage at which the tumor is initially detected and how localized the lesion is. Early diagnosis usually results in successful treatment before metastasis and signifies a better outcome [5].

Recommended preventive techniques to reduce breast cancer morbidity and mortality include breast self-examination (BSE), clinical breast examination (CBE), and mammography. CBE and mammography require hospital visit and specialized equipment and expertise whereas BSE is an inexpensive tool that can be carried out by women themselves [6].

Even though BSE is a simple, quick, and cost-free procedure, the practice of BSE is low and varies in different countries. Several reasons like lack of time, lack of self-confidence in their ability to perform the technique correctly, fear of possible discovery of a lump, and embarrassment associated with manipulation of the breast have been cited as reasons for not practicing BSE [6]. There is evidence that women who correctly practice BSE monthly are more likely to detect a lump in the early stage of its development, and early diagnosis has been reported to influence early treatment to yield a better survival rate [7]

Health education and communication have been found to promote health seeking behavioral change with sufficient utilization and compliance to breast cancer prevention and screening strategies. However, no previous research was done in the study area and awareness about breast cancer among Ethiopian women is not well documented.This paper, therefore, attempts to assess the level of knowledge and attitude towards breast cancer and practice of self breast examination.

\section{METHOD AND MATERIALS}

\subsection{Study Areaand period}

This study was conducted from January to June 2013 inMekelle University which is one of the higher learning institutions found inEthiopia. Mekelle University is located in Mekelle, capital city of Tigray Regional State, $783 \mathrm{kms}$ away from Addis Ababa, capital city of Ethiopia. The University has eight colleges and forty two departments.According to the statistics obtained from student service center, it has a total number of 20,452 regular undergraduate students .Of those number of students 6,340 were females [8],[9]. The university has two clinics and one specialized referral hospital all providing reproductive and other health care services mainly for the in school students and other catchment populations of Tigray regional state

\subsection{Study design and Source population}

An institution based descriptive cross-sectional study employing quantitative method was undertaken. The source population of this study was all regular female undergraduate students in Endayesus and Adi-Haki campuses in Mekelle University. Study populations were randomly selected regular undergraduate female students on which the actual study was conducted. Postgraduate, Mentally and/or physically incapable students were excluded from the study.

\subsection{Sample size determination and Sampling Procedure}

Sample size was determined using sample size formula for estimating a single population proportion with the assumption that margin of error, confidence interval, design effect and expected non-response rate to be 5\%,95\%, 2 and 10\%, respectively. Additionally, the proportion of knowledge of students about breast cancer was considered to be $50 \%$.

$$
\mathrm{n}=\frac{(\mathrm{z})^{2} \mathrm{p}(-\mathrm{p})}{\mathrm{d}^{2}}
$$

Where $\mathrm{n}=$ estimated sample siz; $\mathrm{Z}=$ confidence limit $(1.96), \mathrm{P}=$ prevalence $(50 \%), \mathrm{d}=$ marginal error $(5 \%)$; 


$$
\mathrm{n}=\frac{(1.96)^{2} \times 0.5(1-0.5)}{(0.05)^{2}}
$$

Since the study population is less than 10,000 finite population correction formulas was applied.

$$
\begin{aligned}
& \mathrm{nf}=\frac{\mathrm{n}}{1+\left(\frac{n}{N}\right)}: \text { Where } \mathrm{nf}=\text { desired sample size; } \mathrm{n}=\text { the calculated sample size; } \mathrm{N}=\text { total population } \\
& \mathrm{nf}=\frac{384}{1+384 / 5693}=360 ; \text { Adding } 10 \% \text { non response rate and design effect of } 2 \text { the total sample size was } \\
& \text { calculated to be } 792 \text { students. }
\end{aligned}
$$

The study employed mulit-stage sampling technique. After calculating the sample size, all colleges and class year of study were considered in the sampling process to select the study subjects. First, the University was stratified in to seven colleges and the sample was distributed to each college using probability proportional to their size. Then, using simple random sampling technique (SRS) 21 departments were selected from among the seven colleges. The required number of regular female undergraduate students (sample size) was again distributed to the departments and each year of study using probability proportional to size.

Then, population frames were prepared for each year of study from their rosters in collaboration with the student service director. Finally, the study subjects were selected using simple random sampling technique from their respective year of study.

\subsection{Data collection technique and instrument}

Structured standard self-administered questionnaire was designed and used by reviewing previous similar literatures [10],[11]. It included questions related to knowledge and attitude towards breast cancer and practice of breast self examination. The questionnaire was first prepared in English and then translated to Amharic. To check its consistency it was translated back to English. Ten 10th grade completed data collectors who were familiar with Amharic language distributed the questionnaires. Two BSc nurses with similar work experience were assigned to supervise the data collection process. Training was given for data collectors and supervisors for two days. In the training session the data collectors were oriented on the objective of the study, way how to collect the data and keep confidentiality of information obtained from respondents. All the collected data was checked for completeness, accuracy and consistency by the supervisors and principal investigator.

\subsection{Data quality control and management.}

The questionnaire was pre-tested in Sheba University College (Private University College in Mekelle town) regular female undergraduate students prior to the actual data collection to ensure quality, clarity, understandability and completeness of the data. Depending on the result of the pre-test, correction and modification was made on the questionnaire before actual data collection on the study population was started. Two supervisors and the principal investigator were supervising the data collection processes and necessary correction was made on time. English version questionnaire was translated to Amharic and then back to English by different language experts to the consistency of the data. Data collectors were ten nurses and adequate training was for two days about the process of data collection.

\subsection{Data processing and analysis}

Data were coded, entered and cleaned. Data analysis was carried out using SPSS version 16 software package. Simple descriptive statistics such as frequencies,means, and standard deviations were done as appropriate.

\subsection{Ethical Consideration}

Ethical approval was obtained from the ethical review committee of Mekelle University, College of Medicine and Health science. Letter of co-operation was written from Mekelle University to respective departments. Clear communication was made with the department heads and the study participants about the purpose and the procedures of the study. Informed consent was obtained from each respondent. Participants were assured that they would never face any problem for participating in the study.Privacy, confidentiality and justifiable benefits were maintained. 


\section{RESULTS}

\subsection{Socio-Demographic Characteristics of undergraduate students}

A total of 760 undergraduate regular female studentsparticipated giving a total response rate of $96 \%$. More than half of the respondents aged between 20-21(54.3\%) and only $6(0.9 \%)$ of them were older than 25 years. Majority of the respondents 645(84.5\%) were Orthodox Christian, followed by Muslim 78(10\%). Regarding their marital status about 555(80.8\%) respondents were single. Nearly half $329(43.7 \%)$ of the respondents educational level were first year followed by $234(30.8 \%)$ second year students. Of the 760 students included in this study, $23(3.03 \%)$ mentioned that they have breast problems and 48 (6.3\%) responded that they have family history of breast cancer as shown in Table 1.

Table 1. Socio-demographic characteristics of under graduate regular female students, in Mekelle University, Tigray region, Ethiopia, $2013(\mathrm{n}=760)$

\begin{tabular}{lcc}
\hline Socio-demographic characteristics & Number & Percent \\
\hline Age category & 2 & \\
$<18$ & 186 & 0.3 \\
$18-19$ & 407 & 24.5 \\
$20-21$ & 124 & 54.3 \\
$22-23$ & 25 & 16.5 \\
$24-25$ & 6 & 3.3 \\
$>25$ & & .9 \\
Marital status of the respondent & 555 & 73 \\
Single & 40 & 5.2 \\
Married & 153 & 20.1 \\
Living with partner & 12 & 1.58 \\
Other & & \\
Religion of the respondent & 645 & 84.5 \\
Orthodox & 78 & 10.5 \\
Muslim & 33 & 4.5 \\
Protestant & 4 & 0.5 \\
Others & & \\
Level of education & 329 & 43.2 \\
First year & 234 & 30.8 \\
Second year & 160 & 21.1 \\
Third year & 37 & 4.7 \\
Fourth year & 760 & 100 \\
Total & & \\
Has breast problem & 23 & 3.8 \\
Yes & 737 & 96.2 \\
No & & \\
Has family history of breast cancer & 48 & 6.5 \\
Yes & 712 & 93.5 \\
No & & \\
\hline & & \\
\hline & &
\end{tabular}

\subsection{Knowledge about risk factors of breast cancer}

Concerning the knowledge of respondents, smoking was the most common risk factor identified by $542(71.3 \%)$ of the participants followed by alcohol consumption $336(44.2 \%)$ and high fat diet $295(38.8 \%)$ as shown in Table 2 .

Table 2. Knowledge of undergraduate regular female students about risk factors of breast cancer in Mekelle University, Tigray region, Ethiopia, $2013(\mathrm{n}=760)$

\begin{tabular}{lc}
\hline \multicolumn{1}{c}{ Risk factors of breast cancer } & Correct Response Number $(\%)$ \\
\hline Increasing age & $160(21.1)$ \\
Positive family history of cancer & $158(20.8)$ \\
High fat diet & $295(38.8)$ \\
Smoking & $542(71.3)$ \\
Race/Ethnicity & $139(18.3)$ \\
Alcohol consumption & $336(44.2)$ \\
First child at late age & $135(17.8)$ \\
Early onset of menarche & $72(9.5)$ \\
Late menopause & $137(18.0)$ \\
Stress & $267(35.0)$ \\
Mean Score (SD) & $2.95(1.81)$ \\
\hline
\end{tabular}




\subsection{Knowledge of early warning signs of breast cancer}

Regarding their knowledge about the signs and symptoms of breast cancer, 601 (79.10\%) and 578 (76.10\%) of them knew that breast cancer presents as a pain or soreness in the breast and painless breast lumprespectively. Majority of the respondents explain non-lump symptoms of breast cancer such as discharge from the breast and change in the size of the breast as shown in Table 3.

Table 3. Knowledge regarding Signs and Symptoms of breast cancer among undergraduate regular female students, Mekelle University, Tigray region, Ethiopia, 2013 ( $n=760)$

\begin{tabular}{lcc}
\hline \multicolumn{1}{c}{ Signs and Symptoms of Breast Cancer } & \multicolumn{2}{c}{ Correct response } \\
& Number & $\%$ \\
\hline Lump in the breast & 578 & $76.10 \%$ \\
Discharge from the breast & 451 & $59.30 \%$ \\
Pain or soreness in the breast & 601 & $79.10 \%$ \\
Change in the size of the breast & 408 & $53.70 \%$ \\
Discoloration /dimpling of the breast & 299 & $39.30 \%$ \\
Ulceration of the breast & 384 & $50.50 \%$ \\
Weight loss & 211 & $27.80 \%$ \\
Changes in the shape of the breast & 292 & $38.40 \%$ \\
Inversion/pulling in of nipple & 237 & $31.20 \%$ \\
Swelling or enlargement of the breast & 441 & $58.00 \%$ \\
Lump under armpit & 316 & $41.60 \%$ \\
\hline
\end{tabular}

\subsection{Knowledge of early detection measures of breast cancer}

In terms of means of diagnosis, CBE was the most common means of detecting breast cancer, mentioned by $654(86.10 \%)$ of the participants, followed by SBE and ultrasound $452(59.5 \%)$. Regarding their practice, $315(41.40 \%)$ of the participants reported that they know how to perform self-breast examination and a small number $96(12.60 \%)$ of the participants responded that they know the recommended age to start self-breast examination. Similarly, a small number $62(17.7 \%)$ of the participants correctly identified the recommended frequency for self-breast examination as shown in Table 4.

Table 4. Knowledge regarding early detection measures of breast cancer among under graduate regular female students, Mekelle University, Tigray region, Ethiopia, 2013 ( $\mathrm{n}=760)$

\begin{tabular}{lcc}
\multicolumn{1}{c}{ Questions } & \multicolumn{2}{c}{ Correct response } \\
& Number & $\%$ \\
\hline Pathological examination (Fine Needle Aspiration Cytology) & 290 & $38.20 \%$ \\
Self Breast Examination (SBE) & 452 & $59.50 \%$ \\
Clinical Breast Examination (CBE) & 654 & $86.10 \%$ \\
Mammography & 298 & $39.20 \%$ \\
Ultra sound & 452 & $59.50 \%$ \\
Do you know the recommended age to start SBE? & 96 & $12.60 \%$ \\
Do you know how to perform SBE? & 315 & $41.40 \%$ \\
Do you know how often SBE should be done? & 145 & $19.10 \%$ \\
How often SBE should be done? (Monthly) & 62 & $17.70 \%$ \\
How often CBE should be done? (Once in a year) & 312 & $42.10 \%$ \\
Know the recommended age to start mammography examination (At 40) & 13 & $1.70 \%$ \\
\hline
\end{tabular}

With regard to the knowledge score, $1.4 \%, 3.6 \%$ and $22.1 \%$ of the participants were classified as having Good knowledge $(>70.0 \%)$ on the risk factors, early detection measures and early warning signs of breast cancer respectively. Overall, $75.9 \%, 20.4 \%$ and $3.7 \%$ of the participants were classified as having Poor $(\leq 50.0 \%)$, Moderate $(51.0 \%-70.0 \%)$ and Good $(>70.0 \%)$, respectively as shown in Figure 1. 


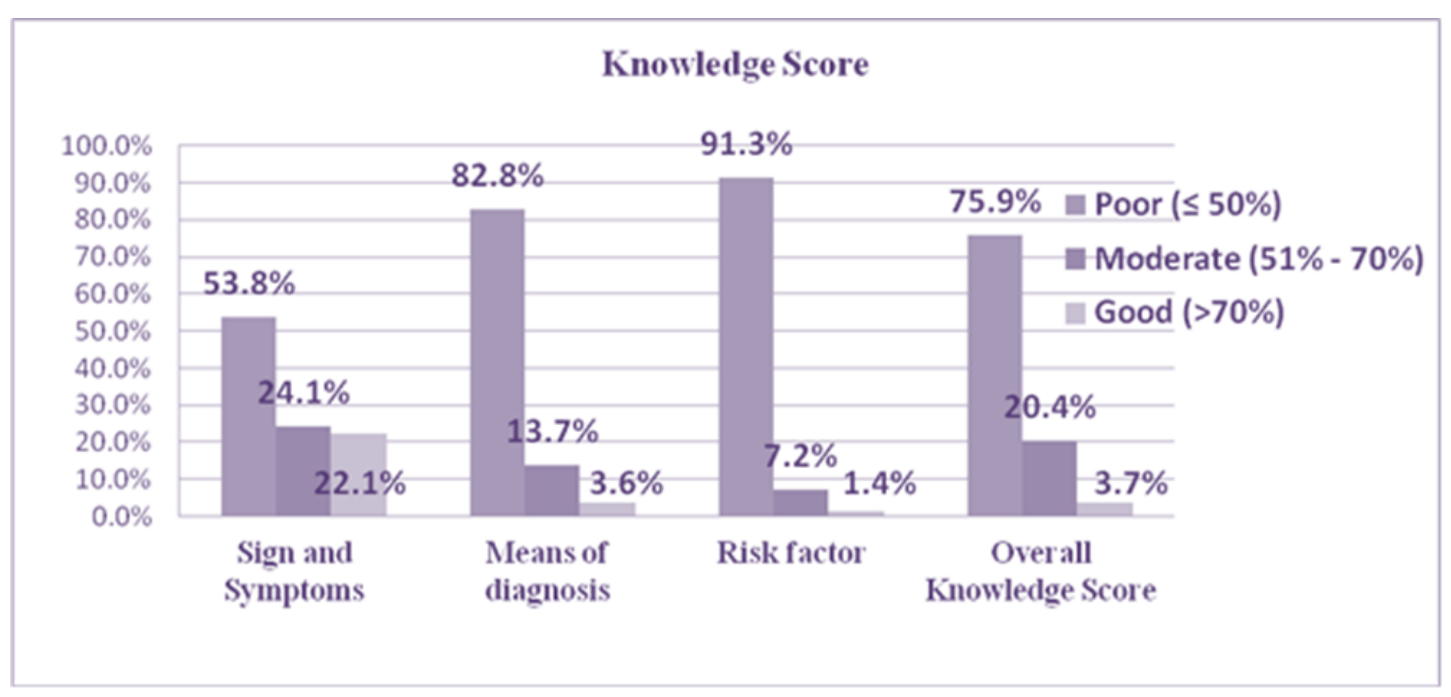

Figure 1. Knowledge score on risk factors, means of diagnosis and sign and symptoms of breast cancer among under graduate regular female students,Mekelle University,Tigray region, Ethiopia, 2013 ( $n=760$ )

\subsection{Attitude of undergraduate regular female students towards Breast Cancer}

Most 424 (55.5\%) of the participants believed that breast cancer is not curable disease, and 465 (63.8\%) believed that long time survival (> 5 year) after being diagnosed with breast cancer is rare. Majority of the participants $606(79.7 \%)$ replied that they would consult a doctor if they developed breast lumps, while only $285(37.50 \%)$ said that they would agree to undergo mastectomy if deemed necessary (Table 5).

Majority of the participants, $612(80.5 \%)$, replied that they would allow a male doctor to examine their breast, while $148(19.5 \%)$ said they will not allow a male doctor to examine their breast. Participants were asked about their perceived risk of breast cancer. Accordingly, 459 (60.4\%) replied that they don't know their perceived risk. While another $77(10.1 \%)$ said that they are not at risk of developing breast cancer at all as shown in Table 5.

Table 5. Attitude towards breast cancer among under graduate regular female students, Mekelle University,Tigray region, Ethiopia,2013 ( $\mathrm{n}=760)$

\begin{tabular}{|c|c|c|c|}
\hline Attitude questions & & Number & $\%$ \\
\hline \multirow[t]{2}{*}{ Believe breast cancer is a curable disease } & Yes & 336 & $44.20 \%$ \\
\hline & No & 424 & $55.80 \%$ \\
\hline \multirow[t]{2}{*}{ Believe Long time survival ( $>5$ year) after breast cancer is rare } & Yes & 275 & $36.20 \%$ \\
\hline & No & 465 & $63.80 \%$ \\
\hline \multirow[t]{3}{*}{ Consult to a doctor } & Yes & 606 & $79.70 \%$ \\
\hline & No & 26 & $3.40 \%$ \\
\hline & Don't know & 128 & $16.80 \%$ \\
\hline \multirow[t]{3}{*}{ Agree to perform Mastectomy } & Yes & 285 & $37.50 \%$ \\
\hline & No & 119 & $15.70 \%$ \\
\hline & Don't know & 356 & $46.80 \%$ \\
\hline \multirow[t]{2}{*}{ Allow male doctor to examine your breast } & Yes & 612 & $80.50 \%$ \\
\hline & No & 148 & $19.50 \%$ \\
\hline \multirow[t]{5}{*}{ Perceived risk of breast cancer } & Not at risk & 146 & $19.20 \%$ \\
\hline & Lower risk & 77 & $10.10 \%$ \\
\hline & Medium risk & 67 & $8.80 \%$ \\
\hline & Higher risk & 11 & $1.40 \%$ \\
\hline & Don't know & 459 & $60.40 \%$ \\
\hline \multirow[t]{6}{*}{ Do you think you have any risk factors? } & None & 271 & $35.70 \%$ \\
\hline & 1 risk factors & 93 & $12.20 \%$ \\
\hline & 2 risk factors & 6 & $0.80 \%$ \\
\hline & 3 risk factors & 152 & $20.00 \%$ \\
\hline & $>3$ risk factors & 6 & $0.80 \%$ \\
\hline & No response & 232 & $30.50 \%$ \\
\hline
\end{tabular}




\subsection{Practice of early detection measures}

Students were asked if they practice early detection measures as a means of diagnosis of breast cancer. Based on the finding, majority of the participants 477 (62.8\%) replied they did not practice SBE. Only 283 (37.2\%) participants practiced SBE. Of the participants who practiced SBE, $201(71.0 \%)$ practiced SBE monthly, $259(97.00 \%)$ started practicing SBE at age less than 25 Years.

The most common reason for not practicing SBE mentioned by the study participants was not having breast problem175 (57.4\%) followed by not knowing how to do SBE 76 (24.9\%) as shown in Table 6.

Table 6. Self breast examination practice of under graduate regular female students, Mekelle University,

Tigray region, Ethiopia, 2013

\begin{tabular}{|c|c|c|c|}
\hline Variables & & Number & $\%$ \\
\hline \multirow[t]{2}{*}{ Practice BSE $(n=760)$} & Yes & 283 & $37.20 \%$ \\
\hline & No & 477 & $62.80 \%$ \\
\hline \multirow[t]{4}{*}{ Frequency of SBE $(n=283)$} & Once in a month & 201 & $71.00 \%$ \\
\hline & Once in 3 month & 36 & $12.70 \%$ \\
\hline & More than once in quarter of a year & 41 & $14.50 \%$ \\
\hline & Never in a year & 5 & $1.80 \%$ \\
\hline \multirow[t]{3}{*}{ Age SBE started $(n=283)$} & $<25$ of age & 259 & $97.00 \%$ \\
\hline & $25-30$ & 2 & $0.70 \%$ \\
\hline & $30-35$ & 6 & $2.20 \%$ \\
\hline \multirow[t]{7}{*}{ Reasons for not practicing SBE $(n=477)$} & I don't have breast problem & 175 & $57.40 \%$ \\
\hline & I don't think I should & 21 & $6.90 \%$ \\
\hline & I don't know how to do that & 76 & $24.90 \%$ \\
\hline & Carelessness & 6 & $2.00 \%$ \\
\hline & I don't think it is necessary & 3 & $1.00 \%$ \\
\hline & Unsure about its benefit & 6 & $2.00 \%$ \\
\hline & more than one reason & 18 & $5.90 \%$ \\
\hline \multirow[t]{2}{*}{ Practice CBE $(n=760)$} & yes & 108 & $14.20 \%$ \\
\hline & no & 652 & $85.80 \%$ \\
\hline \multirow[t]{3}{*}{ Frequency of $\mathrm{CBE}$} & Once & 63 & $69.20 \%$ \\
\hline & 1-3times & 16 & $17.60 \%$ \\
\hline & 3-5 times & 12 & $13.20 \%$ \\
\hline \multirow[t]{9}{*}{ Reasons for not practicing CBE $(n=477)$} & Concern about extra money & 28 & $5.00 \%$ \\
\hline & Concern about extra time & 6 & $1.10 \%$ \\
\hline & Fear of out come & 8 & $1.40 \%$ \\
\hline & Too young to participate & 39 & $6.90 \%$ \\
\hline & No sign symptom of breast cancer & 235 & $41.80 \%$ \\
\hline & No one recommended & 153 & $27.20 \%$ \\
\hline & Unsure about the benefit & 51 & $9.10 \%$ \\
\hline & Other & 24 & $4.30 \%$ \\
\hline & More than one reason & 18 & $3.20 \%$ \\
\hline
\end{tabular}

\section{DISCUSSION}

This institution based cross-sectional study attempted to explore knowledge and attitude of breast cancer and its early detection measures among undergraduate regular female students in Mekelle University, Tigray region, Ethiopia.

The finding of this study showed that respondents with good knowledge score for risk factors, early detections measures and warning signs of breast cancer was $1.4 \%, 3.6 \%$ and $22.1 \%$ respectively. This is slightly lower as compared to other similar studies conducted among female university students in Malaysia, Iraq and Nigeria [12]-[14]. This overwhelmingly poor knowledge score of female students may be explained by the notion that even though this disease condition poses serious burden to the public indefinitely, the healthcare system has been almost exclusively focusing on communicable diseases so far and noncommunicable diseases were ignored for years, particularly in resource poor countries like Ethiopia.

In this study, $71.3 \%$ and $44.2 \%$ of respondents knew that smoking and alcohol consumption increased the risk of developing breast cancer respectively. This finding is higher as compared to evidence from Nigeria [15], where $45.92 \%$ and $25.51 \%$ of the respondents cited smoking and alcohol consumption as risk factors of breast cancer respectively.

As opposed to evidence from Malaysia [12], where only $8.5 \%$ and $27.5 \%$ of the study participants failed to recognize family history of breast cancer and increasing age as risk factors of breast cancer, this study revealed that majority $79.2 \%$ and $78.9 \%$ of the respondents were not knowledgeable that family history of breast cancer and increasing age are risk factors of breast cancer. Regarding the knowledge of participant about early warning signs of breast cancer, this study showed that pain and lump in the breast were the most common warning signs of breast cancer mentioned by $79.10 \%$ and $76.10 \%$ of the respondents

Awareness of Breast Cancer and its Early Detection Measures among Female Students .... (Tesfay Hailu) 
respectively.Moreover, dimpling of the breast and lump under armpit were mentioned by only $39.3 \%$ and 41.6\% participants respectively unlike to the findings from Malaysia and Jeddah [12],[16].

The finding of this study indicated that respondents had better awareness of CBE than SBE. It indicated that $86.1 \%$ of the respondents correctly identified CBE as early detection measure of breast cancer .This is higher than evidence from Nigeria[15]. It reveals a potential pitfall in educating women about breast cancer screening. It isnecessary to educate them on the differences as well as therespective role of breast cancer screening procedures/modalities and the associated guidelines. It is foreseeablethat if women perceive BSE to be equivalent to CBE, theymay decide not to visit a medical provider under theassumption that the BSE alone is adequate screening.However, a higher proportion of respondents of this study failed to recognize SBE as a means for early detection of breast cancer. In contrary to the finding from Nigeria [15], this study reported that $41.0 \%$ of the respondents did not know self-breast examination as early detection method of breast cancer. However, this finding was higher than evidence from Nigeria, [17] in which only $6.4 \%$ of the respondents identified BSE as detection mechanism. Despite slight variation among studies, the knowledge of respondents about BSE is poor. This implies that information, education and communication works are very limited.

These findings also showed that the recommended breast self examination once a month is not popular in an environment where there is no active nationalscreening programme. This study reported that among those who know breast self-examination only $12.60 \%$ and $17.70 \%$ of the participants know the recommended age when SBE should start and the frequency of SBE respectively. This is by far lower than report from Nigeria, and Angola [14],[15],[18].

The finding of this study showed that a significant proportion $62.8 \%$ of the study participants reported that they have never practiced self-breast examination. This was almost in line with evidence from Malaysia, Nigeria, Iraq and Nigeria [12],[15],[19],[20]. But it is higher than another study done in Virginia [14]. This low level of Breast self-examination practice may be attributed to the notion that chronic diseases like breast cancer are not due attention at all levels of the health care system. In line with study from Nigeria and Malaysian [19],[21], the finding of this study showed that the major reason participants mentioned as a barrier to practicing breast self-examination was lack of knowledge how to perform.

When interpreting the finding of this study some limitations should be considered. First, the cross sectional nature of the data made it impossible to reach at causal relationship between the different independent and outcome variables. Second, the source of data for this study, was based on the self-report of respondents, and provided no validation of obtained information with any objective source such as health facility cards. But it is logical to assume that biases are less likely as compared to sensitive issues such as sexual behavior and drug abuse, and respondents were informed about the importance of giving accurate responses and also assured the confidentiality of their responses. The study was conducted among the students of Mekelle University only and therefore might not be a representative of all universities across Ethiopia as well as the general population.

\section{CONCLUSION AND RECOMMENDATION}

The finding of this study revealed that respondents had poor knowledge of risk factors, early detection measures and early warning signs of breast cancer. This implies that the health care system particularly policy makers, health care managers, health care professionals and community based health extension workers are giving limited attention to non-communicable disease like breast cancer despite their public health burden. Moreover, very few of the respondents have practiced self and clinical breast examination.

Scholars argue that practicing BSE make women more "breast aware" and consequently more liable to detect tumors since many breast tumors are discovered by women themselves. In developing countries like Ethiopia where there is no nationwide population-based breast screening mammography program due to limited resources, BSE is considered to be a simple, inexpensive, noninvasive, and non-hazardous intervention, which is not only acceptable, cost-effective and appropriate, but also encourages women to take an active responsibility in preventive health. Thus, until circumstances allow for routine mammography screening in Ethiopia, emphasis should be directed to encouraging women to practice BSE.

The obvious lack of knowledge among the University students highlights the urgent need for educational programs as tools for improving the current knowledge of breast cancer, targeting women through the mass media and perhaps clinical settings. Evidence from different studies indicated that television and radio are the most popular media and can reach a wide audience. Thus, television and radio broadcasts should be used to disseminate the required information pertaining breast cancer. In addition, available data suggest that people prefer to learn about cancer-related issues from their doctors and health organizations. Therefore, proper counseling should be routinely given by healthcare providers within 
hospitals and clinics to improve knowledge of breast cancer. Conduct further study involving students from other University of the country and the general population to appreciate the existing gap in Knowledge and Attitude of breast cancer and practice of self-breast examination.

\section{ABBREVIATIONS}

BSE: Breast Self-Examination; MDG: Millennium Development Goals; FNAC: Fine Needle Aspiration Cytology; KAP: knowledge, attitude, practice; BCC: Behavioral change communication; WHO: World health organization; CBE: Clinical Breast Examination, IEC: Information, education, communication

\section{Competing interests}

The authors declare that they have no competing interests.

\section{Authors' contributions}

TH designed the study, participated in the data collection, performed analysis and interpretation of data and drafted the paper and prepared all versions of the manuscript.

HB and DH assisted in the design, approved the proposal with some revisions, participated in data collection, analysis and revised subsequent drafts of the paper. Both authors read and approved the final manuscript.

\section{REFERENCES}

[1] Ferlay J., Bray F., Pisani P., Parkin D. M., "Globocan 2000: Cancer incidence, Mortality and Prevalence Worldwide," IARC Cancer Base No. 5. [1.0]. Lyon, France, IARC, 2001.

[2] WHO, "Breast cancer: prevention and control," 2014. Available at http://www.who.int/entity/cancer/detection/en/.

[3] Seif N. Y., Aziz M. A., "Effects of breast self-examination training program on knowledge, attitude and practice of a group of Working Women," Journal of the Egyptian Nat Cancer Inst, vol/issue: 12(2), pp. 105-115, 2000.

[4] Ethiopian Cancer Association, "Fight against tobacco to reduce the Risk of cancer through Anti tobacco youth clubs in Ethiopia," 2008. Available at http://www.yeeca.org/Projects.htm.

[5] D. M. Parkin, "Cancer in developing countries," Trends in Cancer Incidence and Mortality Cancer Surveys, vol/issue: 19(20), pp. $519-555,1994$.

[6] Karayurt O., Ozmen D., Cetinkaya A. C., "Awareness of breast cancer risk factors and practice of breast selfexamination among high school students in Turkey," BMC Public Health, vol. 8, pp. 359, 2008.

[7] Petro-Nustas W., Mikhail B. I., "Factors associated with breast self-examination among Jordanian women," Public Health Nursing, vol. 19, pp. 263-71, 2002.

[8] Mekelle University, http://en.wikipedia.org/wiki/Mekelle_University.

[9] Mekelle University, student service center, regular students statistics of the 2012/13 academic.

[10] S. Arshad, K. P. Williams, A. Mabiso, S. Dey, A. S. Soliman, "Evaluating the Knowledge of Breast Cancer Screening and Prevention among Arab-American Women in Michigan J Canc Educ," 2010.

[11] Oluwatosin O. A., Oladepo O., "Knowledge of breast cancer and its early detection measures among rural women in Akinyele Local Government Area, Ibadan, Nigeria," BMC Cancer, vol. 6, pp. 271, 2006

[12] Hadi M. A., Hassali M. A., Shafie A. A., Awaisu A., "Evaluation of breast cancer awareness among female university students in Malaysia," Pharmacy Practice, vol/issue: 8(1), pp. 29-34, 2010

[13] N. A. S. Alwan, W. M. Al-Attar, F. N. Tawfeeq, "Knowledge, attitude and practice regarding breast cancer and breast self-examination among a sample of the educated population in Iraq," Eastern Mediterranean Health Journal, vol/issue: 18(4), pp. 339, 2012.

[14] Isara A. R., Ojedokun C. I., "Knowledge of breast cancer and practice of breast self -examination among female senior secondary school students in Abuja, Nigeria," J Prev Med Hyg, vol. 52, pp. 186-190, 2011.

[15] Okolie, Uchenna Virginia, "Breast self -examination among female undergraduates in Enugu, Southeast, Nigeria," International Journal of Nursing and Midwifery, vol/issue: 4(1), pp. 1-7, 2012.

[16] W. A. Milaat, "Knowledge of secondary-school female students on breast cancer and breast self-examination in Jeddah, Saudi Arabia," Eastern Mediterranean Health Journal, vol. 6, pp. 338-343, 2000.

[17] Oluwatosin O. A., Oladepo O., "Knowledge of breast cancer and its early detection measures among rural women in Akinyele Local Government Area, Ibadan, Nigeria," BMC Cancer, vol. 6, pp. 271, 2006.

[18] M. N. Sambanje, "Breast cancer knowledge and awareness among university students in Angola," Pan African Medical Journal, vol. 11, pp. 70, 2012.

[19] U. M. D. Gwarzo, K. Sabitu, S. H. Idris, "Knowledge and practice of breast self- examination among female undergraduate students of ahmadu Bello university Zaria, northwestern Nigeria," Annals of African Medicine, vol/issue: 8(1), pp. 3-4, 2009.

[20] F. O. Kayode, T. M. Akande, G. K. Osagbemi, "Knowledge, attitude and practice of breast self -examination among female secondary school teachers in ilorin, Nigeria," European Journal of Scientific Research, vol/issue: 10(3), pp. 43-45, 2005.

[21] R. A. Al-Naggar, "Practice and Barriers toward Breast Self-Examination among Young Malaysian Women," Asian Pacific Journal of Cancer Prevention, vol. 12, pp. 1174-75, 2011. 